\title{
¿QUEDARSE TRAS EL PROPIO CERCADO, O SEGUIR EL CAMINO DE DOMEYKO IHACIA UN MUNDO ABIERTO?*
}

\section{MARCIN KULA ${ }^{*}$}

En la historia de Polonia, desde hace mucho tiempo, coexisten y, a veces luchan entre sí, dos tendencias: quedarse tras el propio cercado o salir de éste, abriéndose al mundo. Tal vez en otros países también ocurra lo mismo. Sin embargo, yo me permitiré hablar brevemente sobre el país de donde provengo y del cual vino a Chile Ignacio Domeyko, nuestro respetable compatriota, en cuya memoria nos hemos reunido.

La nobleza polaca que dominaba el país durante la época moderna tenía mucho apego por sus costumbres, era xenófoba y con frecuencia se interesaba en las tierras ubicadas al Oriente del país, antes que al Occidente. En particular, los polacos no se apresuraron a emprender expediciones al lejano continente americano. La nobleza veía la fuente de sus riquezas más en sus tranquilas fincas antes que en expediciones aventureras. Los comerciantes de Gdansk no aceptaron enviar sus barcos cuando, en 1525, Carlos V les propuso tomar parte de una expedición hacia las tierras recién descubiertas. Los contactos posteriores de este principal puerto polaco con América fueron casi nulos durante largos siglos.

Las asambleas de la nobleza muchas veces exigieron prohibir a la juventud noble el viajar a Occidente para que ésta no pierda sus costumbres y, lo más seguro, para que a su regreso no se convierta en rebelde al comparar las experiencias adquiridas con la situación de su propio país. La contrarreforma, más bien conservadora del estado de cosas antes que propulsora de una apertura del país, fue fuerte en las tierras polacas.

\footnotetext{
- Marcin Kula, Universidad de Varsovia.
} 
Esto no debía traer solamente efectos negativos. El sarmatismo del siglo diecisiete, una de las corrientes artísticas más interesantes en la literatura y las bellas artes polacas, constituyó una creación totalmente local, no imitó en nada o casi nada los modelos foráneos y algunas veces produjo obras verdaderamente valiosas.

En los marcos de esta civilización con un alto grado de xenofobia, aunque no necesariamente mayor que en otras partes, también tenían lugar fenómenos contrarios. Los hijos de los magnates, y también de los nobles, eran a pesar de todo enviados al extranjero, para que obtengan el "roce" debido. Los insistentes llamados en las asambleas para que se limiten estos viajes dan testimonio por supuesto no solamente de la aversión de la nobleza hacia aquellos, sino también de que se trataba de un fenómeno relativamente frecuente y duradero. En realidad, la Polonia tradicional, en cierto modo, tenía que abrirse. El sistema de democracia nobiliaria, coronado con la elección libre de los reyes, permitía un menor aislamiento que el despotismo oriental presente del otro lado de la frontera. Polonia era un estado de muchos grupos étnicos y religiosos, se extendía en grandes regiones, estuvo unido en su tiempo con Lituania, poseía contactos exteriores con el Occidente a través del catolicismo dominante y de la relación con Roma, mientras que como resultado de la geografía se situaba entre el Oriente y el Occidente de Europa.

En tal estado existían de manera natural, por así decirlo, ciertas premisas de apertura. Dicho sea de paso, su existencia se comprobó muchas veces de manera palpable. Cuando en el siglo XVIII Polonia se encontró en una situación de peligro, las ideas de la ilustración que venían de Francia generaron tendencias hacia la reforma. Estas se expresaban tanto en la adopción del vestido francés en lugar de las vestimentas tradicionales de la nobleza, así como, y lo más importante, en la elaboración de la Constitución (1791), para sus tiempos bastante moderna, la primera en Europa y la segunda en el mundo (después de la constitución de los Estados Unidos).

Las reformas aquí señaladas no salvaron a Polonia. Sus tierras quedaron completamente repartidas entre Rusia, Prusia y Austria (1795). Puede decirse que la inclusión de las respectivas tierras polacas en los límites de estos tres imperios significó en cierto senticlo su apertura: enlazó las tierras orientales con Moscú, las sureñas con Viena y las occidentales con Berlín. Muchos especialistas polacos se formaron en estos países y también allí trabajaron. La derrota de las sublevaciones nacionales polacas del siglo XIX originó la marcha de emigrantes polí- 
ticos hacia Occidente (Domeyko fue uno de ellos), y la situación económica de las tierras polacas a finales del siglo XIX e inicios del XX originó una ola de emigración económica hacia Occidente, incluyendo también América del Sur. Aquellos emigrantes acercaron, en cierto sentido, a Polonia hacia el mundo.

Al mismo tiempo, la pérdida de la independencia y el sueño de su recuperación concentraron intensamente el pensamiento de los polacos en sus propios asuntos, los encerraron en cierto sentido en su propio gusto. Las acciones a favor de la independencia eran las prioritarias para muchos, incluyendo a las personas más ilustradas. Algunos emigrantes polacos, esparcidos por el mundo más pensaban en Polonia antes que en los países de residencia. Los emigrantes económicos con frecuencia se situaban en los nuevos terrenos con poco éxito y en consecuencia cultivaban los recuerdos y se aferraban a la idea de que alguna vez regresarían; mientras tanto deberían conservar la lengua polaca y la cultura, que no podía desarrollarse en el país subyugado.

Es verdad que muchos emigrantes polacos, y entre ellos Domeyko ocupa un buen lugar, supieron interesarse y preocuparse por los problemas de los países donde les tocó vivir. Muchos vinculaban su esperanza de recuperar la independencia de Polonia con los acontecimientos de la historia universal, especialmente con las acciones de Napoleón. Precisamente, en los destacamentos que luchaban de parte de aquél nació el himno nacional polaco. Los más grandes de entre los emigrantes polacos, empezando por Adam Mickiewicz, el principal poeta nacional polaco, anhelaban la hermandad de los pueblos en la lucha contra los tiranos y consideraban que la guerra de los pueblos devolvería la libertad a Polonia.

Cuando la guerra de los pueblos llegó, aquellos emigrantes románticos del siglo diecinueve ya habían muerto. Y trajo la Polonia que ellos habían sonado. Sin embargo, el país renacido, antes que a la apertura, estaba dispuesto, a concentrarse en sí mismo. Las dificultades del proceso de ingreso a la independencia, la inseguridad de las nuevas fronteras y la lucha por ellas, y también, aunque no menos importante, la dramática guerra de 1920 con Rusia, obligaron a concentrar la atención sobre sí mismo. La existencia de minorías nacionales bastante numerosas en el estado, recién reconstituido y por lo tanto caracterizado por una gran tensión de la idea nacional, también obligaha a pensar en lo que era propio. Esto se veía favorecido por el bajo grado de modernización de la sociedad. Como resultado, uno de los movimien- 
tos sociales de masas más fuertes, que ingresó entonces a la escena política, recurría al discurso nacionalista e incluso chovinista.

$\mathrm{Al}$ mismo tiempo, el país recién constituido estableció contactos oficiales con otros estados, entre ellos con estados latinoamericanos. Hasta en círculos más cercanos al mariscal Pilsudski habían oficiales fascinados por este continente. Polonia construyó un nuevo puerto en el Báltico; en aquel entonces un puerto significaba una ventana al mundo.

La Polonia renacicla se vinculó al Occidente en parte como resultado de las antiguas tendencias civilizatorias y del más o menos antiguo temor ante Rusia (URSS). La intelectualidad polaca en la época de entre guerras tenía la mirada puesta sobre todo en París, con frecuencia también en Berlín y algunas veces en Londres.

La segunda guerra mundial trajo resultados bastante ambivalentes desde el punto de vista de la capacidad de apertura (aislamiento) de la sociedad polaca. El drama de la guerra expulsó hacia Occidente una masa de personas que de esta forma, involuntaria y desdichada, conocieron el mundo y, al quedarse en el extranjero después de la guerra, continuaron ese puente natural que descle antes los emigrantes constituían entre otros países y Polonia. La causa polaca dependía de los aliados occidentales; gracias a su ayuda y su armamento funcionaba el gobierno polaco en la emigración en Londres y el ejército polaco luchaba en el frente occidental. La conspiración antihitleriana en el país ocupado, también le agradecía la ayuda al Occidente. Sin tal ayuda, a pesar de todo el patriotismo de los guerreros de la clandestinidad, no hubiera podido desarrollar, según parece, el más fuerte movimiento de resistencia en la Europa ocupacla.

Por otra parte la ocupación concentró la atención del país en los asuntos de la supervivencia de la gente, en los asuntos polacos, en las represiones hitlerianas y en la lucha contra ellas. El modelo de pensamiento en categorías étnicas (y no de ciudadanía) de nuevo se volvió dominante. Muy poco se percibió el sufrimiento de los juclíos polacos y a este grupo se le acusó fuertemente de colaborar con la URSS en los territorios orientales. Durante la guerra tuvieron lugar agudos conflictos con la minoría ucraniana; conflictos en los cuales resulta prácticamente imposible hallar la hipotética culpa originaria. Aun cuando el Occidente estaba representado por los aliados, el vecino más cercano, Alemania, era precisamente el enemigo. También era difícil abrirse hacia el Este, es decir hacia Rusia. Esto debido a su calidad cle enemigo de los años 1939-1941, en su calidad de país sobre el cual no había buena memoria en Polonia, como país que no ocultaba sus pretensio- 
nes respecto a una parte considerable de las tierras del estado polaco de preguerra y, finalmente, como país, cuyas ambiciones por dominar la Polonia de postguerra eran fáciles de prever. El abandono por parte de Rusia del Levantamiento de Varsovia (1944) a su propia suerte, sin prestarle ayuda en la lucha contra los hitlerianos, aumentó aun más el sentimiento de soleclad de los polacos, algo que completó la conferencia de los aliados en Yalta, donde se dejó a Polonia en la esfera de las influencias soviéticas.

Se puede valorar el hecho que, a pesar de la atención fuertemente concentrada en los asuntos propios, la última gran declaración de la clandestinidad antihitleriana polaca no comunista subrayó la necesidad de apertura de la futura Polonia liberada hacia Checoslovaquia o hacia Lituania.

La dominación del país por parte de la URSS después de la guerra, las represiones realizadas por los comunistas contra los miembros del movimiento no comunista de resistencia contra Hitler, el cierre de las fronteras, para luego reabrirlas limitadamente, así como las dificultades de la vida cliaria, no favorecían la apertura cle Polonia hacia el mundo después del año 1945. Aquellos, quienes constituían el soporte del poder comunista, con frecuencia eran bastante xenófobos. I3ien por causa de éstos, o bien por causa de la táctica comunista, el nuevo régimen de muy buena gana acentuaba aquello que era propio. Paradójicamente, y a pesar de sus principios teóricamente internacionalistas, era capaz de ser bastante nacionalista, incluso chovinista.

Las conexiones de la RPp (República Popular de Polonia) y la URSS encerraban al país en su propio cercado y no solamente en dirección occidental, sino también respecto a otros países del campo socialista. La gente en Occidente no comprendía lo insignificantes que, por ejemplo, eran los contactos profesionales, los contactos espontáneos de los especialistas polacos con los especialistas de otros países comunistas. Las relaciones oficiales y el intercambio de delegaciones eran estimulaclos, no así los contactos espontáneos y privados. Debiclo a que el comunismo ordenaba tener amistad con aquellos países y simultáneamente hasta la comicidad hacía propaganda de sus logros verdacleros o supuestos, de hecho se impeclía el interés espontáneo por éstos.

Al mismo tiempo todo este comunismo polaco, especialmente a partir de 1956, cuando se derrumba el culto a Stalin, fue menos restrictivo que en otros estados del campo socialista. La Polonia comunista nunca llegó a ser tan cerrada como otros "países hermanos". Desde Polonia se viajala hacia Occidente, en las bibliotecas universitarias se podían 
leer libros occidentales. No todos, por supuesto, aunque si muchos. Las humanidades y las ciencias sociales después de 1956 se encontraban en Polonia a un nivel relativamente alto y mantenían contacto con la ciencia mundial. No en todos los campos era así, pero si en muchos. Fernand Braudel valoraba la historiografía polaca; hasta alguna vez dijo que existen dos escuelas históricas de consideración: la francesa y la polaca.

La intelectualiclad polaca aún vivía con la miracla puesta en París; aun cuando allí a veces se sentía insegura (El famoso poeta polaco Zbigniew Herbert escribía a sus amigos en 1967: "Es que todos estamos cosidos de dos partes no ajustadas. El almita eslava, y sobre ella puesta la ropita europea. Ni acá, ni allá"\$0).

El contacto entre el país y los polacos que vivían en la emigración se mantuvo durante gran parte del período comunista. Muchos de aquellos estaban bastante encerrados en su identidad polaca, aunque algunos abrían el camino hacia el mundo para el pensamiento nacional. Los polacos incesantemente se sentían parte de Europa, de aquella Europa occidental. Esto lo expresaba diariamente su fascinación por la civilización occidental, por diferentes "gadgets", la Coca-Cola, los buenos automóviles. Generalmente, por supuesto, no se percibía los diferentes elementos negativos que esta civilización representa.

Descle el punto de vista analizado, la rebelión de los años ochenta contra el comunismo fue bastante interesante. Ésta resultó no tanto de los elementos negativos del comunismo, uno de los cuales era nuestro aislamiento de Europa, como del hecho que el comunismo, tal como se claba en Polonia, nunca pudo (¿o quizás a veces no quiso?) aislarnos totalmente del mundo. Este mundo occidental, el mejor, podía ser visto a través de la puerta entreabierta. Sólo quedaba abrirla de par en par. En este contexto, el movimiento Soliclariclad, que realizó esto fue dual: bastante polaco y a la vez bastante abierto al mundo. Destacaba la importancia de la soberanía nacional, de la tradición polaca, del catolicismo en su versión polaca. Al mismo tiempo en cierto senticlo funcionaba en la óptica mundial, mantenía contacto con los sindicatos de diferentes países, contaba con la ayuda de las sociedades occidentales

"no "Queridos animalitos..." Cartas de Zhignieu' Herhert a sus amigos Magdalena y Zhigniew Czajkouski (en polaco), edición y comentarios de Magdalena Czajkowska, PIW, Varsovia 2000, p. 103. 
y de hecho la conseguía. Llamaba a la acción a los obreros de los países del ex campo socialista; confiaba en que teníamos la oportunidad de encontrarnos en una Europa libre y feliz.

La dualidad señalada también se expresa en las actitudes que se tomahan respecto a asuntos concretos. Por ejemplo, en Soliclaridad se daba el caso de actitudes chovinistas, aunque al mismo tiempo el movimiento ayudaba a las minorías nacionales. El orgtillo polaco se veía lisonjeado por la percepción que se tenía de los polacos: la de un pueblo que abría camino para otros pueblos que luchaban por la libertad. $Y$ es que realmente en los años ochenta en el país se luchaba, al mismo tiempo, no sólo por la libertad de Polonia.

Después de la caída del comunismo, Polonia se abrió ampliamente al exterior. En un primer período esta fue una apertura caricaturesca, expresacla entre otras cosas en la masiva afluencia de la peor chatarra occidental a nuestros bazares. En aquel momento las principales calles de Varsovia parecían un gigantesco "mercado de pulgas" parisino. Estos fenómenos patológicos fueron limitándose con el tiempo (jaunque, por otra parte, se fortalecieron, por ejemplo, las conexiones internacionales del mundo de la delincuencia!).

Al mismo tiempo en aquel entonces la apertura psicológica hacia Europa era bastante fuerte; los sondeos mostraban un alto grado de actitud proeuropea. Existían por supuesto movimientos políticos expresamente xenófobos, aunque no tenían gran éxito.

Con el paso de los años sin embargo aparecieron algunos fenómenos, que perturbaron la imagen optimista de una sociedad abierta hacia el mundo. En primer lugar, Europa resultó con relación a Polonia menos abierta de lo que los polacos, tal vez ingenuamente, esperaban. Puso condiciones, presentó exigencias. Resulta difícil sorprenderse. Tampoco sorprende que éstas actuasen un poco como una ducha fría. Hay que recordar que los polacos se consideraban parte de Europa, y hasta subrayaban sus méritos en la defensa del Occidente frente a los turcos en el siglo XVII y frente al comunismo en el año 1920. Con su propia elección libre de los reyes se presentaban como una democracia temprana. Estaban y siguen apegados al recuerdo de la ya mencionada Constitución de 1791 como la primera de Europa. A través de sus fuertes vínculos con la Iglesia Católica se consideran a sí mismos como europeos y frecuentemente como aquellos que deben recordarle a Europa los valores católicos.

La actitud abierta hacia el mundo también disminuyó cuando muchos grupos sociales comprendieron que la competencia de la eco- 
nomía europea occidental los colocaba frente a desafíos difíciles de superar. Igualmente importante es que la transformación en Polonia tuvo y tiene lugar acompanada de grandes costos sociales, y hasta de la marginalización de una masa considerable de gente. Este grupo constituye terreno fértil para una mezcla ideológica sincrética bastante peligrosa: la nostalgia por el comunismo con acentos de xenofobia. Se puede comprender a estas personas pues tienen motivos para la frustración. Sin embargo, esto no cambia el hecho que ellas constituyan un gran peligro potencial para la continuidad de la apertura de la sociedad polaca.

En la resistencia que hoy aparece en Polonia respecto al acercamiento hacia Europa y el mundo aparecen mezclados ideas falsas sobre las perspectivas y problemas bastante reales. Hay que disipar las primeras y resolver los segundos. Sobre todo se necesita tratar de realizar una política económica tal que no empuje a la gente a la desesperación y la obligue a aferrarse a sus propias cercas como las únicas buenas, ya que por lo menos les resultan conocidas.

Se puede entrar a Europa con toda la riqueza de la cultura propia. Su conciliación con los logros de otros no es, o por lo menos no debería de ser, una tarea como hallar la cuadratura del círculo o hacer huevos revueltos sin romper el cascarón. La diferenciación, por ser creativa, hasta será necesaria para el mundo que se uniformiza como efecto de las características de nuestra civilización. Sin embargo, la necesidad de conciliar lo propio y lo universal, no se puede hacer entender al desocupado, al campesino que no tiene que hacer con sus productos, al pequeño agricultor que escucha que lo mejor es que desaparezca de la faz de la tierra, al minero que se queda sin trabajo después de haber laborado muchos anos, al jubilado que a cluras penas tiene lo necesario para vivir. Esto no se explica a las personas empobrecidas que ven un creciente número de automóviles lujosos en las calles, a las personas sin probabilidades de adquirir vivienda y que ven aparecer nuevas y lujosas villas, a los médicos y maestros mal pagados, a los enfermos pobres, que tienen dificultad para encontrar asistencia médica, lo que tampoco es menos importante y no se explica a aquellos ideólogos, que encuentran un soporte en la frustración de las gentes. Todos ellos van a recurrir a sus propios valores como que representan el apoyo más seguro y van a dar la espalda a los ajenos por ser nuevos, desconocidos y, en consecuencia, potencialmente peligrosos.

Hay que recordar que la corriente que antepone "lo nuestro" ante la apertura ha sido en la historia de Polonia siempre fuerte y de alguna 
manera se ha codificado en la mentalidad colectiva. Domeyko, entre otros ilustres antepasados nuestros, puede ser patrono de la corriente de actitudes y pensamientos abiertos, pero ya póstumamente muy poco puede conseguir en esta esfera. La generación presente debe de ayuclarse a sí misma.

- Traducido del polaco por Francisco Rodriguez. 